\title{
DESIGNING TWO-PART GREYWATER FEES: CONCEPTUAL FRAMEWORK AND EMPIRICAL EVIDENCE FROM GERMANY
}

\author{
BENEDIKT ROTERS \& MARK OELMANN \\ Institute of Economics, Hochschule Ruhr West - University of Applied Sciences, Germany.
}

\begin{abstract}
The wastewater sector in Germany - fragmented local natural monopolies under cost regulation and vulnerable to political intervention - comprises roughly 6.900 fee models. Unlike pricing schemes in other network economies, the prevalent fee models are quite simple as customers pay a single fee per $\mathrm{cbm}$. Such a fee results in high incentives to reduce water consumption and greywater discharge simultaneously, which complies with the Water Framework Directive (WFD). However, the fee lacks financial, economic and social sustainability. Implementing an additional fixed fee seems to be a reasonable measure to remedy these shortcomings, although the fixed fee share in overall revenue remains an important control parameter to guarantee compliance with the WFD. Having argued for a two-part fee, two parameters for the fixed fee component must be defined: First, the fee base and second, the fee rate. Out of a wide range of possible fee bases, the 'Number of dwelling units in a residential building' is not just stable but also corresponds to the costs-by-cause principle and generates manageable transaction costs. However, transaction costs also depend on the extent to which gains and losses among customers due to the fee model switch occur. Testing different fee models with household data in three German cities of different population size, the authors find evidence that the number of dwelling units combined with a digressive rate structure results in less absolute gains/losses for customers. This finding is model-inherent and can be used to rethink fee models just based on the cbm. The authors recommend the fee model switch when (1) water consumption per capita is decreasing, (2) migration of water consumption is high and (3) resource costs are low.
\end{abstract}

Keywords: fixed fee, greywater fee, sustainability concept, tariff design

\section{INTRODUCTION}

The wastewater disposal sector in Germany consists out of nearly 6.900 utilities, mostly under the ownership of local municipalities [1]. Unlike in network economies as for example the electricity sector, no incentive-based regulation schemes apply for the wastewater sector, which economists define as 'natural monopoly'. Instead, a form of cost-regulation applies. Cost-regulation does not imply individual monitoring of costs with focus on efficiency, but rather a monitoring of (1) cost accounting principles - among others mandatory full costrecovery - and (2) tariff design principles, both on request. These principles are encoded in European, national, federal and municipal legal institutions. Cost-regulation schemes are accompanied by voluntary benchmarking rounds, which emphasise efficiency. However, benchmarking reports for public just contain aggregated data and no utility-specific information. Therefore, benchmarking supports dedicated utilities with valuable information about key performance indicators and efficient process design, but limits external pressure to reduce costs. Each utility seems therefore to be well protected. At the same time, each utility is vulnerable to internal pressure via political intervention, which might put pressure on full application of the cost-recovery principle in order to keep the customer fees low. Yearly comparisons of wastewater fees, e.g. from the association of tax payers in North Rhine-Westphalia [2], might explain such behaviour. However, instead of debating if fees are 'too high or too low', different fee models, which evolved in the above-mentioned area of 
tension, are discussed. The focus lies solely on fee models for greywater [3], ignoring fees for precepitable water, which cover separate costs although technical separation is often missing (e.g. combined sewer systems). Fee models for non-household customers are also excluded, as these need deeper analysis of pollution-based fees [4].

Binding legal rules restrict the design of fee models. These rules are not always very specific, but reasonable regarding their fundamental principles, as several objectives [5] need to be balanced. One major principle is the costs-by-cause principle, which makes customers pay fees according to what extent they contribute to costs. The wastewater disposal sector shows a high percentage of fixed costs, mainly due to the provision of infrastructure. Percentages up to $85 \%$ are common, but $95 \%$ are possible as well [6]. Such numbers raise the question, what the main service of a wastewater utility is. According to the numbers, it cannot be the disposal and purification of greywater, but rather the provision of sewer system and wastewater treatment plant. Just the former service depends on the quantity of greywater, the latter one is quantity-independent. From an economic point of view, quantity-independent services should be covered by fixed fees - a two-part fee model (volumetric fee + fixed fee) would be reasonable [7]. However, according to an empirical survey, 31 out of 271 cities in North Rhine-Westphalia use two-part fee models. The modified volumetric-only fee (based on metered freshwater consumption \pm adjustments, for example, metered freshwater for gardening) is predominant, a statement with can be generalised for whole Germany as spot checks in other federal states show. In Europe, a mixed picture can be found as the following Figure 1 illustrates.

The survey shows the relevance of fixed fees in the ten biggest cities with regard to population size in selected countries. Except Berlin, no other German city uses two-part-tariffs. The cities in the Netherlands show the opposite: All fee models solely rely on fixed fees, based on property value. British and Swiss cities rely heavily on the volumetric fee, as the above calculations for a model household indicate. Though using a fixed fee, the revenue share covered by the fixed fee component is likely to fall short of the fixed costs share. Austrian cities show the widest range of shares covered by the fixed fee with two cities roughly meeting the fixed costs share. Overall, it is obvious that, relative to the high percentage of fixed costs, the volumetriconly fee plays a way too dominant role in fee model design, not just in German cities.

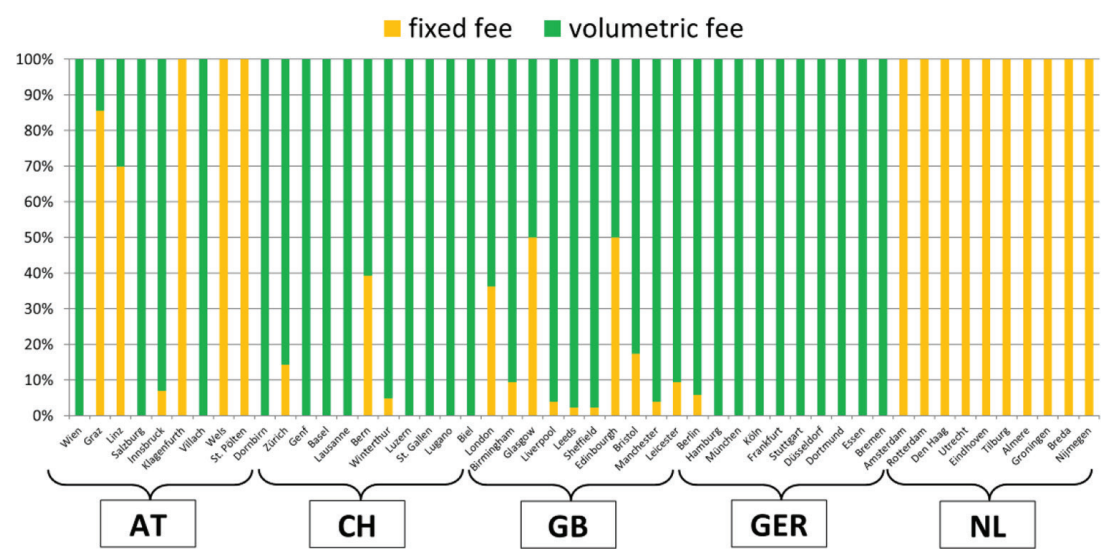

Figure 1: Billing share of fixed fee and volumetric fee for a single-family household (150 cbm) in selected countries 2015. 
In this paper, the authors argue that two-part fee models with sufficient revenue share covered by the fixed fee improve sustainability ( $\rightarrow$ Chapter 2 ). However, a fee model switch creates distributional effects ( $\rightarrow$ Chapter 3 ), which might be the reason why volumetric-only fees prevail. Finally, a different fee model is derived ( $\rightarrow$ Chapter 4 ), which is not just sustainable, but also balances the extent of gains/losses due to the fee model switch.

\section{JUSTIFICATION OF TWO-PART FEE MODELS}

'Sustainability' is a composed criterion, which is here applied to assess the introduction of a fixed fee component into the fee model [8]. Four sustainability dimensions are considered: Economic, ecological, financial and social sustainability [9].

The already mentioned costs-by-cause principle belongs to economic sustainability. In case of a volumetric-only fee, customers pay according to their consumption. Households with low consumption, among them holiday homes, pay less than households with high consumption. However, consumption is not the main driver of costs and these customers utilise the provided infrastructure anytime. Therefore, they have to pay for the provision of infrastructure independent of how much greywater these customers dispose into the sewer system. If they do not, customers with the ability to reduce consumption retrieve from funding the infrastructure and the financial burden is redistributed - the financing mechanism does not correspond to the costs-by-cause-principle. A fixed fee component prevents such redistribution and allocates the costs of infrastructurzze provision to those customers who benefit from it. The volumetric fee still allocates variable costs, e.g. energy costs, to customers according to their greywater quantity. However, both fees components should finance different services.

Economic sustainability also requires marginal cost pricing, which does not apply for the volumetric-only fee because of cross-subsidisation mechanisms. With cost-recovering fees, introducing a fixed fee implies a lower volumetric fee. In case the fixed fee fully covers fixed costs, the volumetric fee reflects marginal costs and customers can make efficient consumption and investment decisions. Without fixed fee, customers tend to reduce consumption beyond the economic optimum and invest too much in water-efficient technologies, respectively investments that reduce the disposed/billed greywater quantity (e.g. metering devices for gardening).

Ecologic sustainability requires a tariff design that gives incentives to preserve water resources and prevents pollution. The latter point can be excluded as households tend to have homogenous, manageable dirt freights in their greywater (unlike non-household customers) and comprehensive pollution meters are not an option. However, Art. 9 Water Framework Directive (WFD) requires 'that water pricing policies provide adequate incentives for users to use water resources efficiently'. As volumetric greywater fees exceed in most European countries the volumetric freshwater price [10], incentives from the wastewater disposal side are in comparison stronger. This is also true for countries without organisational separation [11], where greywater fees are included in the water price. At least from consumer perspective, wastewater disposal and water supply sector are anyway part of the same value chain. However, introducing a fixed greywater fees lowers the volumetric fee and incentivises water saving. Therefore, the volumetric-only fee fosters ecological sustainability and every fixed fee decreases the extent to which this dimension is fulfilled.

Financial sustainability requires stable revenue to cover costs occurring in the billing period. The wastewater utility faces price and quantity risks, where the latter one are risks due to volatile consumption patterns. In case of higher than expected consumption among all 
customers, revenue exceeds costs and vice versa. Both should be avoided as short-term extra revenue has to result in lower fees during the following periods and missing revenue requires intermediate financing measures. The latter one is a concern for municipalities with decreasing water consumption per capita and/or emigration of water consumption. With given costs and volatility of consumption, the volumetric-only fee maximises the difference between revenue and costs. Consequently, the implementation of a fixed fee improves periodic costrecovery as a stable fee covers fixed costs. The flat rate (NL) is in this context not sustainable as e.g. energy costs vary with greywater quantity and should covered via a volumetric fee.

Social sustainability does not necessarily imply social tariffs but rather questions whether the volumetric-only fee negatively affects low-income households. One circumstance support this hypothesis: Low-income households primarily inhabit houses with multiple dwelling units. Empirical evidence shows that such inhabitants in general react less sensible to fee adjustments. Single-family houses and non-household customers have higher 'price-elasticities' [12] as they perceptibly benefit from quantity adjustments in case of increasing/ decreasing prices. As water consumption is declining for several years now and costs increase at the same time not just because of inflation but also because of quality improvements, volumetric only fees rise upwards. Single-family houses and non-household customers reduce water consumption to avoid rising fees. Houses with multiple dwelling units more and more have to bear the financial burden. A self-sustained process emerges where higher fees induce lower consumption and the financial burden for low-income households is likely to rise. The fixed fee slows the 'fee spiral' down and removes social sustainability deficits. This argument applies primarily for municipalities with decreasing total consumption.

Overall, the volumetric-only fee fosters ecological sustainability, but lacks economic, financial and social sustainability. Such imbalance between the four sustainability dimensions can be corrected by introducing a fixed fee. Although this weakens ecological sustainability, the fixed fee strengthens the remaining three dimensions, restores a balance between all four dimensions and improves overall sustainability.

Something that should not be forgotten is that a fee model switch results in gains/losses for customers. If these distributional effects are expected to be substantial, the likelihood of realising the new fee model shrinks. Customers will not accept high losses and obstruct the fee model switch, which in turn makes transaction costs for implementation high. Fee models therefore should carefully balance gains and losses to achieve implementation in the shortrun while realising long-term benefits due to improved sustainability. However, designing the fixed fee leaves several options for the wastewater utility and understanding the effects of a model switch is essential. The following chapter provides first insights into such effects.

\section{EFFECTS OF A FEE MODEL SWITCH}

In Germany, owners of residential buildings pay wastewater fees, as long as the individual dwelling units are not equipped with metering devices. Newer legislation enforces water meters for each dwelling unit, so that households in new constructed buildings pay the fee directly and not via intermediate distribution by the property owner. Given the situation of newer buildings, the individual household $i$ pays a volumetric-only greywater fee $p_{1}^{v}$ for each unit of consumption $x_{i}$. The fee sums up to

$$
p_{1}^{v} \times x_{i}
$$

A two-part fee model with fixed fee component $p_{i}^{f}$ results in total fees of 


$$
p_{2}^{v} \times x_{i}+p_{i}^{f} .
$$

Assuming that $\theta$ is the revenue percentage share covered by the fixed fee component, eqn (2) changes to

$$
(1-\theta) p_{1}^{v} \times x_{i}+p_{i}^{f}
$$

Assuming that the fixed fee component is the same for each customer $\left(\rightarrow p_{i}^{f}=p^{f}\right)$, the cost recovery condition equals

$$
\sum_{i=1}^{n} p_{1}^{v} \times x_{i}=\sum_{i=1}^{n}\left[(1-\theta) p_{1}^{v} \times x_{i}+p^{f}\right]
$$

In the equation above, $n$ defines the total number of customers. Simplification and reordering yields

$$
p^{f}=\theta p_{1}^{v} \times \bar{x} .
$$

Given that each customer has to pay the same fixed fee, the fee itself depends on the percentage share in revenue, the single volumetric rate and the average water consumption (neglecting differences between water consumption and volume of greywater), which is defined as $\frac{1}{n} \sum_{i=1}^{n} x_{i}$.
The individual gain/loss $\left(\Delta_{i}\right)$ from the fee model switch is

$$
\Delta_{i}=(1-\theta) p_{1}^{v} \times x_{i}+\theta p_{1}^{v} \times \bar{x}-p_{1}^{v} \times x_{i}
$$

Simplification and reordering shows that an individual gain from the switch occurs when:

$$
x_{i}>\bar{x}
$$

Is the individual water consumption greater than the average water consumption $\bar{x}$, the gain from the reduced volumetric fee compensates for the loss due to the implemented fixed fee. The fixed fee therefore benefits high consumption, as households with less consumption contribute more to the costs of infrastructure provision. The full extent of gains/losses among all customers $\left(\sum \Delta_{i}=\Delta\right)$ equals to

$$
\sum_{i=1}^{n}\left[\left|(1-\theta) p_{1}^{v} \times x_{i}+\theta p_{1}^{v} \times \bar{x}-p_{1}^{v} \times x_{i}\right|\right]
$$

Simplification yields

$$
\Delta=n \theta p_{1}^{v} \times M A D
$$

$M A D$ stands for Mean Average Dispersion and is a common measure of statistical dispersion $\left(\rightarrow M A D=\frac{1}{n} \sum_{i=1}^{n}\left[\left|\bar{x}-x_{i}\right|\right]\right.$ ). As the only control parameter for fee model design is $\theta$, a reduction of gains/losses can only be achieved by lowering the percentage share in revenue covered by the fixed fee component. $M A D$ and $n$ are characteristics of the wastewater disposal district and - thought influenced by the single volumetric fee - exogenous parameters at the moment, the fee model switch is conducted. The initial volumetric fee $p_{1}^{v}$ is set to recover costs and expected to be higher, when the fee spiral evolves. Wastewater utilities 
facing such a problem should therefore react in time as gains/losses c.p. increase with increasing volumetric fee.

However, the lump sum fixed fee does not properly correspond to the costs-by-cause principle. Therefore, the fee base complements previous deliberations, mapping the individual costs of infrastructure provision. The fixed fee extends to

$$
p_{i}^{f}=p_{1}^{f} \times b_{i} .
$$

$b_{i}$ denotes the fee base and is expected to rise as the individually attributable costs of infrastructure provision increase. The 'price' $p_{1}^{f}$ of a single fee base unit $b_{i}$ can be derived via the cost-recovery condition and yields

$$
p_{1}^{f}=\frac{\theta p_{1}^{v} \times \bar{x}}{\bar{b}} .
$$

Each single unit of $b_{i}$ 'pays' the lump sum fixed fee relative to the average value of the fee base among all customers $\bar{b}$. In case all customers show the same characteristic - the wastewater disposal area is completely homogenous (e.g. metering devices are all of the same size) - the fixed fee equals the lump sum fee.

The gains/losses among all customers sum up to

$$
\Delta=n \theta p_{1}^{v} \times \frac{1}{n} \sum_{i=1}^{n}\left[\left|\overline{\boldsymbol{x}} \times \frac{\boldsymbol{b}_{\boldsymbol{i}}}{\overline{\boldsymbol{b}}}-\boldsymbol{x}_{\boldsymbol{i}}\right|\right] .
$$

The latter term is not the MAD itself but rather a fee base weighted MAD. However, the equation shows that for minimising gains/losses $b_{i}$ and $x_{i}$ must be aligned variables. If a wastewater utility intends to establish a fixed fee to mitigate long-term negative effects due to sustainability deficits, but at the same time worries about high transaction costs due to redistribution effects, it should seek for such a fee base that shows the lowest weighted MAD. Making such a choice is a second control parameter to steer gains/losses. However, costsby-cause considerations should be prioritised.

The derivations above comprise linear rate structures. Without going into detail, the assumption can be modified to allow for also digressive or progressive rate structures. In that case, the fixed fee is calculated as

$$
p_{i}^{f}=g\left(b_{i}\right)
$$

$g($.$) is a continuous function with the following properties: (1) \frac{\partial g()}{\partial b_{i}}>0 \rightarrow$ the higher the fee base, the higher the fixed fee; (2.1) $\frac{\partial^{2} g\left(b_{i}\right)}{\partial b_{i}{ }^{2}}>0$ if rate structure is progressive and (2.2) $\frac{\partial^{2} g()}{\partial b_{i} \partial b_{i}}<0$ if rate structure is digressive. Progressive rate structures aren't reasonable in Germany, neither for the volumetric fee ( $\rightarrow$ no severe water scarcity) nor for the fixed fee $(\rightarrow$ no cost progression). However, digressive rate structures seem reasonable as the required infrastructure capacity decreases with regard to the fee base. Assuming that such a connection can be verified by also technical analysis, the wastewater utility can set up a digressive function $g($.$) , which should rely on technical reports to verify the cost digression. The$ 
definition of the function is the third control parameter. For demonstration purposes, the authors assume a digressive function of the form

$$
p_{i}^{f}=p_{2}^{f} \times \sqrt{b_{i}} .
$$

As $p_{2}^{f}$ is determined by exogenous parameters, total gains/losses equal

$$
\Delta=n \theta p_{1}^{v} \times \frac{1}{\boldsymbol{n}} \sum_{i=1}^{n}\left[\mid \overline{\boldsymbol{x}} \times \frac{\sqrt{b_{i}}}{\frac{1}{\boldsymbol{n}} \sum_{i=1}^{n}\left[\sqrt{\boldsymbol{b}_{i}}\right]}-\boldsymbol{x}_{i} \| .\right.
$$

The latter term is also a weighted MAD, but the function $g($.$) changes the weights for \bar{x}$ from function input to function output values. Properly designed functions can substantially reduce the amount of gains/losses. Keep in mind that the cost-recovery-constraint lowers the degrees of freedom by one, so that the functions with more than one free parameter can be selected to be able to reduce the distributional effects. The design of the function - at least in Germany - has to comply with legislation, which constrains free parameterisation in order to keep gains/losses low.

\section{DEVELOPING THE FEE MODEL DESIGN}

The fee model design requires a parameterisation of the three in chapter 3 derived parameters. The concept of sustainability is applied once more to parameterise $\theta$. The costs-by-cause principle is the leading concept for the choice of the fee base. However, other criteria apply, e.g. data availability. For selected fee bases, a proper rate structure can be derived. The selected fee models have been developed for the city of Leichlingen, Germany.

\subsection{Parameterisation of $\theta$}

The Parameter $\theta$ ranges from zero ( $\rightarrow$ volumetric-only fee) to $100 \%$ ( $\rightarrow$ flat rate). If the wastewater utility just wants do reduce distribution effects, the value should be low. In following years, it can be raised without too many distortions. However, other utilities want to raise the share immediately to the target level. Both approaches raise the question, what a sustainable and long-term target level should be.

Both, economic and financial sustainability require $\theta$ being equal to the share of fixed costs $(\approx 85 \%)$. In that case, the volumetric fee equals marginal costs and efficient consumption and investment decisions can be made. It also satisfies potentially the costs-by-cause principle, because volumetric and fixed fee separately cover the costs of the two different services. Cross-subsidisation mechanisms are set off. Any $\theta$ above that level diminishes economic and financial sustainability, because of the deviations from the marginal cost pricing principle and non-periodic cost-recovery. Figure 2 illustrates how $\theta$ affects the degree of sustainability subdivided by the four dimensions.

Ignoring dirt freights, ecological sustainability in general increases with decreasing $\theta$ resp. lower volumetric fee, because of higher incentives to reduce water consumption and preserve water resources. However, disposal areas might not suffer from water scarcity, which implies that resource costs according to the WFD are low and such incentives are dispensable. If 


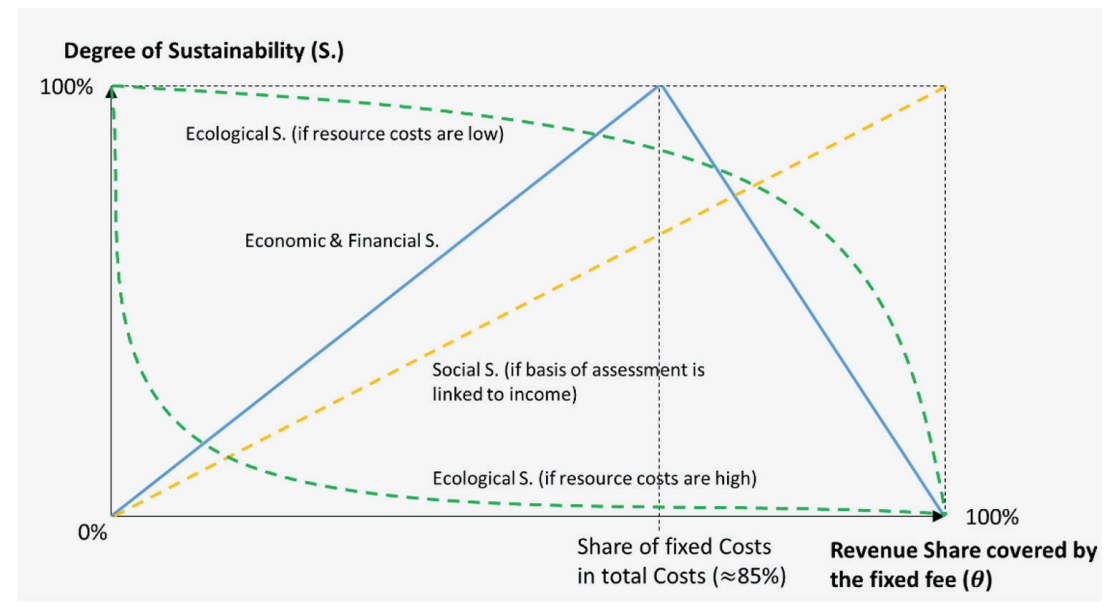

Figure 2: Determinants of $\theta$.

resource costs are low, a higher $\theta$ is justified according to ecological sustainability. The flat rate still incentivises wasteful use of water and should be strictly rejected. On the other hand, a lower $\theta$ might be sustainable, if the sewer systems need to be flushed with freshwater for hygienic purposes. It is therefore important to consider the whole 'environmental balance sheet' to assess this sustainability dimension.

How the degree of social sustainability depends on $\theta$ is uncertain and primarily relies on the fee base. If the base is income-correlated, a $\theta$ might lower the greywater fee for lowincome households. However, freshwater consumption, the basis of assessment for the volumetric rate already shows (weak) correlation with income [13]. Therefore the fixed fee base must be even closer connected to income, if low-income households should gain from the fee model switch. Not debateable is the fact that a substantial $\theta$ helps to stop the fee spiral, which negatively affects low-income-households.

While both, economic and financial sustainability, point towards a $\theta$ of roughly $85 \%$, ecological sustainability requires a lower $\theta$. Even when resource costs are low in Leichlingen, there are substantial legal doubts, which is why the authors vote for a compromise to balance sustainability dimensions. A compromise can be $50 \%$, a quite common value also in the water supply sector. A lower $\theta$ to minimize distributional effects might be reasonable at first glance, but is not necessary as the results in chapter 4.3 show.

\subsection{Selection of the fee base}

The main cost drivers of infrastructure provision are the greywater quantity itself ( $\rightarrow$ wastewater treatment plant) and the network length $(\rightarrow$ sewer system). The fee models in selected European cities often apply fee bases related to quantity. Among them are (1) the size of water metering device, (2) the number of dwelling units (DU) in a residential building, (3) the number of toilets and (4) the number of inhabitants. In addition, (5) the property value and (6) the living space partly reflect the network length. Differentiating between (7) different city areas is also a possible fee base, strengthening the costs-by-cause principle if e.g. infrastructure is 'more valuable' in the city center. 
For a number of reasons, the majority of fee bases seem not appropriate. The property value for example is not directly linked to the disposed greywater quantity so that it cannot meet the costs-by-cause principle. Other criteria for fee base selection are the costs for gathering resp. maintaining the database and of course data availability in general.

In cooperation with the wastewater utility in Leichlingen the authors developed three twopart fee models. The first model based on the size of the metering device (SMD-Model), the second model based on the number of dwelling units (DU-Model) and a third model with combined fixed fee base (Combi-Model). 'Combined' refers to a fixed fee based on (1) the number of dwelling units and (2) the length of the front of a residential building. The former one covers fixed costs of the wastewater treatment plant, the latter one covers fixed costs of the sewer network. As infrastructure costs of the sewer system depend heavily on the network length, the authors found it appropriate to use a measure, which reflects the individual contribution to the provision of the sewer network length. Some notes on the different fee bases:

The size of the metering device and the number of dwelling units in a residential building are common measures in the water supply sector and also used in the wastewater disposal sector. A serious caveat of the metering size stems from the fact that the standard $Q_{n} 2.5$ meter supplies roughly $95 \%$ of all residential buildings. Therefore, the capability to segment customers according to their greywater quantity is poorly. According to technical rules [14], the $Q_{n} 2.5$ meter can supply buildings up to 30 dwelling units, covering a range of 0 to approximately $2000 \mathrm{cbm}$. The underlying logic behind the fee base is that even single-family houses could potentially consume the upper cbm limit allowed by the meter size and dispose the freshwater after usage into the sewer system. However, it totally ignores empirical evidence: Single-family households are very unlikely to consume more than $250 \mathrm{cbm}$. Treating the exception as a rule creates distortions with big residential buildings, in which the meter size is not falsely oversized. For this reason, the weighted MAD for this fee base is quite high and gains/losses expected to be substantial. However, the fee base is popular and widely accepted, which is why the authors decided to include it as benchmark.

The number of dwelling units (DU) in a residential building has more fee base categories (1-DU-Building, 2-DU-Building,...) and can segment customers according to their consumption more precisely. Although the fee base is not able to reflect the network length, it is closely connected to the greywater quantity. The limitation of gains/losses should be easier.

Superior regarding the costs-by-cause principle is the Combi-Model as both cost drivers are covered. However, the front length does not vary with consumption and the distributional effect should be greater. Insofar there is a trade-off: Additional correspondence with the costs-by-cause principle comes at the cost of higher gains/losses.

\subsection{Fee structure}

While there is no justification for meter size and front length to divert from linear fee structure, a digressive rate structure seems to be appropriate for the number of dwelling units. Three arguments based on empirical evidence in Leichlingen and two other partner municipalities can be urged: First, the disposed quantity per dwelling unit decreases with building size. So even if all inhabitants in a building with multiple dwelling units simultaneously dispose greywater, the quantity per DU would be less compared to the quantity of a singlefamily house. Second, the stochastic profile of greywater disposal evens out between the 


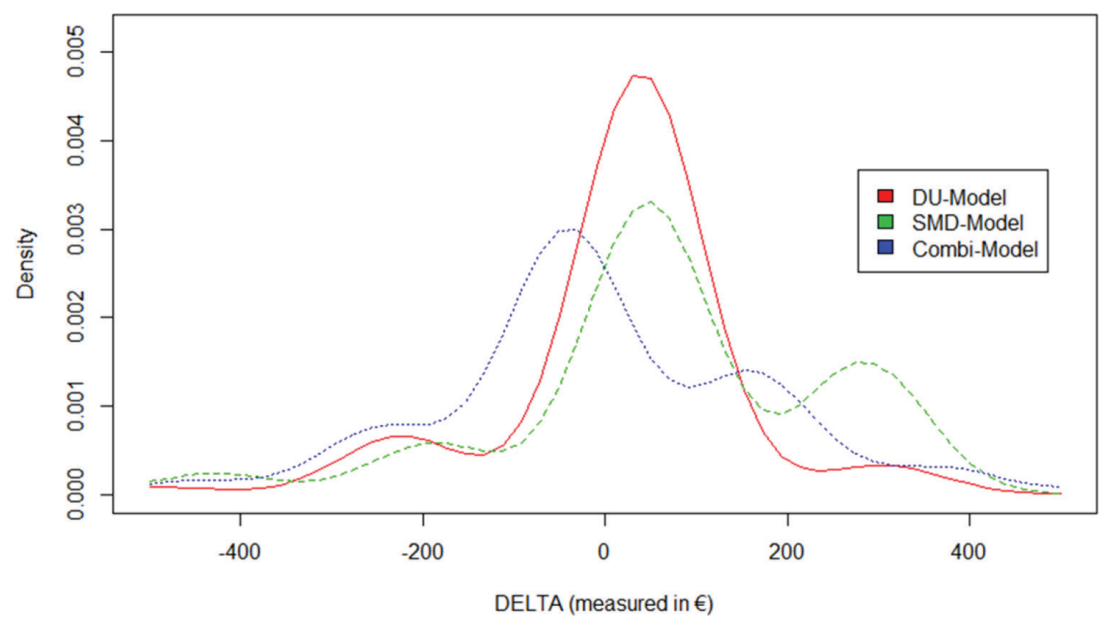

Figure 3: Distribution of gains/losses for customers for different fee models.

different dwelling units in the same building. Third, numbers from Leichlingen indicate that the front length does not increase proportional with increasing number of dwelling units. A 30-DU-Building has less than 30 times the front length of a single-family house. The provided infrastructure is therefore expected to be less for each DU. Cost digression in all three cases justifies a digressive rate structure, which is applied for the number of dwelling units in the DU-Modell and the Combi-Model.

\subsection{Distributional effects of selected fee models}

Knowing that the digressive rate structure also reflects the consumption patterns in Leichlingen, the weighted MAD and consequently the extent of gains/losses is lowest in the DU-Model. Figure 3 pictures the density functions of gains/losses $\Delta_{i}$ at building level for the three different models. Although $\Delta_{i}$ is no random variable, the figure illustrates the distribution of gains/losses very well. The abscissa is limited to $\pm 500 €$. However, some customers gain/loose well above $10000 €$.

Obviously the DU-Model can centralise gains/losses much better around the neutral position $( \pm 0 €)$ than SMD and Combi-Model. This is due to the segmentation capability of DU. The SMD-Model affects, particularly single-family houses with low consumption. As these customers pay the same fixed fee as e.g. 30-DU-Bildings at lower overall consumption, they lose due to the model switch according to eqn. (6). The fixed fee constitutes losses of 200 $400 €$ for this customer group. The effect can be seen at the right tail of the green dashed line. The Combi-Model seems beneficial to most customers as the "likelihood" of gaining from the two-part model peaks at roughly $50 €$. However, a few customers with very high front length bear substantial losses, which would surely provoke resistance.

Both, the SMD-Model and the Combi-Model redistribute more than 30\% of the total greywater revenue. The DU-Model redistributes roughly $16 \%$, a number that is confirmed in two other disposal areas with available data for the DU-Model. Households in different buildings with average consumption patterns gain/loose not more than $5 \%$. In a city with favourable settlement structure, consumption patterns and moderate volumetric-only fee, the maximal 
gain/loss for average customers fell short of $2 \%$. This seems manageable and communicable, so that the authors overall recommend the DU-Model. The model fosters sustainability with given $\theta$ and causes only moderate redistribution among customers, making the model well-balanced.

\section{CONCLUSIONS}

A future-proof greywater fee model can balance different dimensions of sustainability. As the volumetric-only fees lacks economic, financial and social sustainability, two-part fees restore the balance between sustainability dimensions and improve overall sustainability. This is particularly important for municipalities in which water consumption per capita is decreasing and/or water consumption migrates out of the wastewater disposal area. In both cases, a fee spiral starts with negative consequences for sustainability. To properly address ecological sustainability, the share in revenue covered by the fixed fee component should remain below the share of fixed costs. A share of 50\% seems to be a compromise, which applies also in other industries as benchmark. However, when resource costs are low, it is reasonable to raise the level above $50 \%$ and vice versa. A high share also implies that distribution effects are higher, which makes the fee model switch due to transaction costs less likely. To restrict gains/losses among customers, wastewater utilities can choose the fee base and the fee structure to minimise such distributional effects. Both parameters - this is the restriction have to comply with the costs-by-cause principle to guarantee sustainability. Testing three different fee models, the 'number of dwelling units in a residential building' is capable to meet the costs-by-cause principle and reduce gains/losses properly, at least in case of the three cities. To account for reduced consumption per dwelling unit with increasing building size, a digressive rate structure was modelled, which is both, justified by the costs-of-cause principle and favourable in terms of gains/losses. A fee model of this form performs better than two benchmark models. Overall, the authors recommend the number of dwelling units as sustainable fee base, which creates moderate gains/losses and makes the fee model easy to implement.

\section{REFERENCES}

[1] Profile of the German Water sector 2015; ATT et al., available at: https://www.bdew. de/internet.nsf/id/profile-of-the-german-water-sector-2015-de. (accessed 9 March 2017).

[2] Comparison of wastewater fees 2016; Association of tax payers NRW, available at: http://www.steuerzahler-nrw.de/files/75620/8_Abwasser_Gesamttabelle.pdf. (accessed 9 March 2017).

[3] Oelmann, M., et al., Nachhaltige Bestandserhaltung öffentlicher Abwasseranlagen und ihre Refinanzierung, available at: https://www.lanuv.nrw.de/landesamt/forschungsvorhaben/details/?tx_mmkresearchprojects_pi1[uid]=448. (accessed 13 March 2017).

[4] Mogden-Formula; Ofwat, available at: http://www.ofwat.gov.uk/nonhousehold/ yourwaterbill/hownonhousehold/trade/mogden. (accessed 21 July 2015).

[5] American Water Works Association (AWWA), Principles of water rates, fees, and charges - Manual of water supply practices, 6th Ed., Denver, 2012.

[6] Leptien, C., et al., Wirtschaftsdaten der Abwasserbeseitigung 2014, Bad Honnef, 2014.

[7] Coase, R., The marginal cost controversy. Economica, 13, pp. 169-182, 1946. https://doi.org/10.2307/2549764 
[8] Oelmann, M., Roters, B. \& Gawel, E., Sustainable fee models in the wastewater sector, KA Korrespondenz Abwasser, to be published.

[9] Organisation for Economic Co-operation and Development (OECD), Pricing water resources and water and sanitation services, Paris, 2010.

[10] Bundesverband der Energie- und Wasserwirtschaft e.V. (BDEW), Comparison of European water and wastewater prices, VEWA survey, Berlin, 2015.

[11] European Environmental Agency (EAA), Assessment of cost recovery through water pricing, EAA technical report, No 16/2013, Luxembourg, 2013.

[12] Oelmann, M. \& Gendries, S., Auf dem Weg zu einem neuen Tarifmodell in der deutschen Wasser-versorgung. Teil 1: Anforderungen aus Sicht eines Wasserversorgers, Prozessgestaltung und Datengenerierung, in: gwf-Wasser|Abwasser, pp. 820-827, 2012.

[13] Schleich, J. \& Hillenbrand, T., Determinants of Residential Water Demand in Germany, Working Paper Sustainability and Innovation, No. S3, 2007.

[14] Deutsche Vereinigung für Wasserwirtschaft, Abwasser und Abfall e.V. (DWA), Worksheet W 406. 